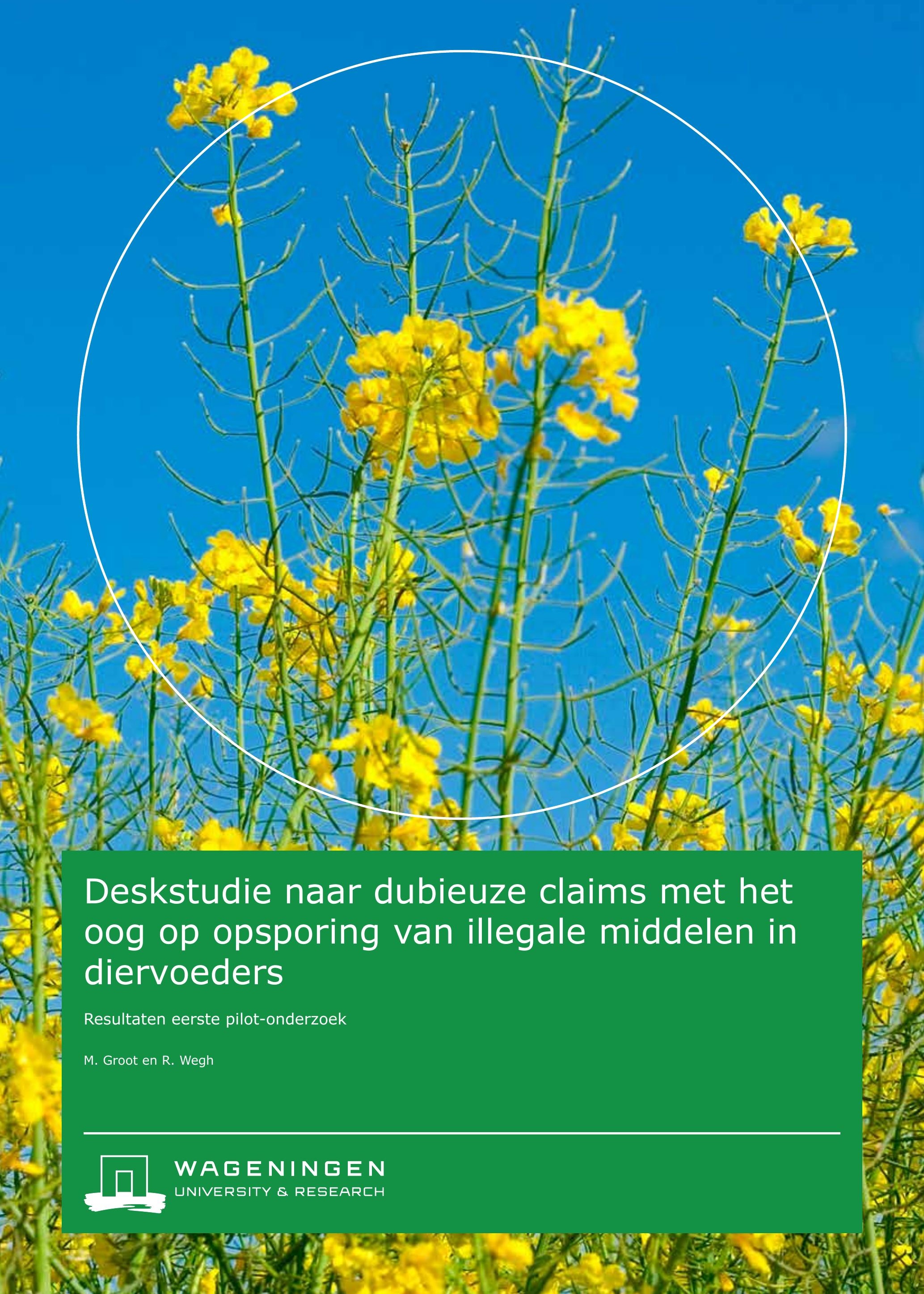





\section{Deskstudie naar dubieuze claims met het oog op opsporing van illegale middelen in diervoeders}

Resultaten eerste pilot-onderzoek

M. Groot en R. Wegh

Dit onderzoek is uitgevoerd door Wageningen Food Safety Research, instituut binnen de rechtspersoon Stichting Wageningen Research en gesubsidieerd door het ministerie van Landbouw, Natuur en Voedselkwaliteit, in het kader van wettelijke onderzoekstaken, programma 2 Voedselveiligheid (WOT-02-004-014).

Wageningen, december 2021

WFSR-rapport 2021.020 
M. Groot en R. Wegh, 2021. Deskstudie naar dubieuze claims met het oog op opsporing van illegale middelen in diervoeders; Resultaten eerste pilot-onderzoek. Wageningen, Wageningen Food Safety Research, WFSR-rapport 2021.020. 14 blz.; 0 fig.; 4 tab.; 0 ref.

Projectnummer: 1227166601

BAS-code: WOT-02-004-014

Projecttitel: Methodeontwikkeling en inventariserend onderzoek diervoeders

Projectleider: R. Wegh

Dit rapport is gratis te downloaden op https://doi.org/10.18174/562103 of op http://www.wur.nl/foodsafety-research (onder WFSR publicaties).

(C) 2021 Wageningen Food Safety Research, instituut binnen de rechtspersoon Stichting Wageningen Research. Hierna te noemen WFSR.

Het is de opdrachtgever toegestaan dit rapport integraal openbaar te maken en ter inzage te geven aan derden. Zonder voorafgaande schriftelijke toestemming van het WFSR is het niet toegestaan:

a. dit door WFSR uitgebrachte rapport gedeeltelijk te publiceren of op andere wijze gedeeltelijk openbaar te maken;

b. dit door WFSR uitgebrachte rapport, c.q. de naam van het rapport of WFSR, geheel of gedeeltelijk te doen gebruiken ten behoeve van het instellen van claims, voor het voeren van gerechtelijke procedures, voor reclame of antireclame en ten behoeve van werving in meer algemene zin;

c. de naam van WFSR te gebruiken in andere zin dan als auteur van dit rapport.

Postbus 230,6700 AE Wageningen, T 03174802 56, E info.wfsr@wur.nl, www.wur.nl/food-safety-research. WFSR is onderdeel van Wageningen University \& Research.

WFSR aanvaardt geen aansprakelijkheid voor eventuele schade voortvloeiend uit het gebruik van de resultaten van dit onderzoek of de toepassing van de adviezen.

WFSR-rapport 2021.020

Verzendlijst:

- Ninca Wentzel (LNV)

- Sandra Doevendans-de Bruin (LNV

- Marjan van Creij (LNV)

- Karen Zwaagstra (NVWA)

- Michiel den Braver (NVWA) 


\section{Inhoud}

1

Inleiding

2

Werkwijze

3

Resultaten

4

Conclusies

10

5

Aanbevelingen

11

Bijlage 1 Risico's

12

Bijlage 2 Verboden stoffen 
$\longrightarrow$ 


\section{$1 \quad$ Inleiding}

Dit rapport is opgesteld in het kader van de Deskstudie gebruik illegale middelen bij claims. In deze deskstudie is een marktonderzoek uitgevoerd naar aangeboden producten met claims, waarna de mogelijkheden tot controle van claims op diervoeders is uitgezocht. De claims waren meestal gebaseerd op de werking van natuurlijke middelen (bijv. kruiden). Met de recente fipronil crisis is echter wel duidelijk geworden dat het toedienen van illegale middelen tot de mogelijkheden behoort. Deze controle is gericht op de aanwezigheid van mogelijke illegale middelen die de geclaimde werking kunnen veroorzaken. Aan de hand van de gevonden aanknopingspunten is hiervoor een analysestrategie worden opgesteld.

Afbakening: Het project focust zich alleen op illegale claims in diervoeders om daarmee de volgende fipronil crisis te voorkomen.

Afbakening: Het project ging alleen om illegale middelen in diervoeders. Hoe voorkom je een volgende fipronil crisis. Er is gezocht naar claims die te mooi zijn om waar te zijn en diergeneeskundige claims, en alleen naar middelen voor in het dier (geen geregistreerde diergeneesmiddelen, geen omgevingsmiddelen), alleen landbouwhuisdieren (varken, pluimvee, rundvee, kleine herkauwers en paarden) en naar mogelijke risico's voor de voedselveiligheid. 


\section{Werkwijze}

Hoewel de titel van het project deskstudie is, werd niet verwacht dat er in de openbare literatuur veel gepubliceerd zou zijn over illegale claims en verboden middelen. Er is daarom gekozen om informatie te verzamelen op een grote internationale veehouderijbeurs (EuroTier 2018), te spreken met specialisten en te zoeken op internet aan de hand van folders van producenten die zijn verzameld op de EuroTier. Daarnaast is informatie verkregen via de NVWA.

Voor de start van het project is een bijeenkomst geweest met stakeholders. Tevens is een gesprek geweest met de VDDN, branchevereniging voor producenten, importeurs en leveranciers van diervoederspecialiteiten en diergezondheidsproducten in Nederland (www.vddn.nl). 


\section{Resultaten}

Uit de bijeenkomst met stakeholders kwamen de onderstaande suggesties naar voren om mogelijke informatiebronnen en indicatoren voor de toepassing van illegale middelen in diervoeder bij (gezondheid)claims in beeld te krijgen.

Onderzochte bronnen:

- Inventariseer en rubriceer de claims die worden gebruikt voor (aanvullende) diervoeders en prioriteer naar waarschijnlijkheid dat illegale middelen zijn toegevoegd ${ }^{1}$

- Inventariseer websites van aanbieders en producenten van (aanvullende) diervoeders en de aangeboden producten

- Onderzoek het aanbod van (aanvullende) diervoeders op beurzen en exposities

- Interviews met producenten van (aanvullende) diervoeders

Deze suggesties zijn door de beperkte tijd voor dit project niet aan de orde gekomen:

- Onderzoek lijsten van biociden, gewasbeschermingsmiddelen en kruiden(preparaten) en prioriteer naar waarschijnlijkheid dat deze als illegale middelen gebruikt kunnen worden in (aanvullende) diervoeders

- Zoek in internet-discussiegroepen van veehouders en in reacties van lezers op vakbladartikelen (boerderij.nl, varkenshouderij.nl, etc. etc.) naar gebruikservaringen met (aanvullende) diervoeders, leveranciers/producenten, afzonderlijke toevoegmiddelen, kruiden, etc.

- Zoek op marktplaats en vergelijkbare sites specifiek bij aanbod van restpartijen etc. naar producten met claims

- Zoek in buitenlandse vakbladen (met name Duits- en Franstalige tijdschriften) naar producten met claims

- Zoek in Melding Ondersteuning Systeem (MOS) van NVWA naar opmerkingen en klachten over effecten van (aanvullende) diervoeders, niet-werkende claims en aanverwante opmerkingen.

De verschillende informatiebronnen gaven een aantal verdachte middelen op basis van de claims, de naam, of het gebrek aan informatie over de inhoudstoffen. De mogelijke risico's zijn weergegeven in Bijlage 1. Bijlage 2 geeft de lijst verboden middelen volgens VERORDENING (EU) Nr. 37/2010, waarvoor geen MRL kan worden opgesteld.

In totaal zijn in de beperkte tijd van het project 36 middelen gevonden. De middelen zijn voornamelijk bestemd voor pluimvee, varkens, duiven en melkvee. De mogelijke risico's zijn te vinden in Bijlage 1 . In Bijlage 2 staan verboden stoffen o.g.v. VERORDENING (EU) Nr. 37/2010

Ze zijn in te delen als:

- Middelen met een onwaarschijnlijke of diergeneeskundige claim en onduidelijke samenstelling (Tabel 1)

- Middelen met een suggestieve naam (hier niet weergegeven). Denk aan bv Bloedluisweg, antiColi, Finitocox, etc.

Daarnaast zijn er middelen gevonden die buiten het kader van dit project vallen, maar te interessant waren om niet genoemd te worden: "bijvangst".

- Middelen bestaand uit verboden diergeneesmiddelen (Tabel 2)

- Middelen voor de omgeving die in aanwezigheid van het dier gebruikt mogen worden (Tabel 3)

- Middelen voor lokale toedieningen met een diergeneeskundige claim (Tabel 4)

- Tabel 1: Middelen met een zware claim en onduidelijke samenstelling 
Tabel 1 Middelen met een zware claim en onduidelijke samenstelling

\begin{tabular}{|c|c|c|c|}
\hline Middel & Samenstelling & Claim & Indicatie \\
\hline $2018-1$ & phytochemicals, onbekend & $\begin{array}{l}\text { werkt net zo goed als } \\
\text { coccidiostatica }\end{array}$ & coccidiose \\
\hline $2018-2$ & phytochemicals, onbekend & $\begin{array}{l}\text { antibacterieel effect en tegen } \\
\text { protozoen }\end{array}$ & Diarree biggen \\
\hline $2018-3$ & $\begin{array}{l}\text { Magnesium (Chloride): } 15000 \\
\text { mg, Sodium (Chloride): } 380 \\
\text { mg, Vitamin C: } 12000 \text { mg, } \\
\text { Plants extracts : } 25 \mathrm{ml} \text { Purified } \\
\text { Water }\end{array}$ & $\begin{array}{l}\text { maakt het bloed onverteerbaar } \\
\text { voor mijten, vormt een toxine } \\
\text { in het bloed }\end{array}$ & bloedluis \\
\hline $2018-4$ & $\begin{array}{l}\text { Calcium, Natriumchloride en } \\
\text { aromatische stoffen }\end{array}$ & $\begin{array}{l}\text { zorgt ervoor dat uw dieren } \\
\text { onaantrekkelijk worden voor } \\
\text { insecten. Het heeft tevens een } \\
\text { rustgevende werking en } \\
\text { ondersteunt een gezond } \\
\text { vederkleed }\end{array}$ & bloedluis \\
\hline $2018-5$ & $\begin{array}{l}\text { natrium chloride, dextrose, } \\
\text { (vitamines aromastoffen) }\end{array}$ & Zet per direct droog & Droogzetten melkvee \\
\hline $2018-6$ & $\begin{array}{l}\text { propyleenglycol, glycerine } \\
\text { mengsel van aromatische } \\
\text { stoffen }\end{array}$ & $\begin{array}{l}\text { geur verdrijft de mijten, betere } \\
\text { voeropname, betere darmflora, } \\
\text { betere stallucht }\end{array}$ & bloedluis \\
\hline $2018-7$ & $\begin{array}{l}\text { phytobiotic, bevat natuur- } \\
\text { identieke stoffen uit } \\
\text { plantmateriaal en vitamines }\end{array}$ & $\begin{array}{l}\text { maskeert de geur van de hen, } \\
\text { werkt als natuurlijk repellent }\end{array}$ & bloedluis \\
\hline $2018-8$ & essentiële olie, vitamines & $\begin{array}{l}\text { therapeutisch effect bij } \\
\text { virusinfecties }\end{array}$ & Enteritis (darmontsteking \\
\hline $2018-9$ & $\begin{array}{l}\text { mengsel van smaakstoffen, } \\
\text { vitamine E, propyleenglycol, } \\
\text { glycerol, technologische } \\
\text { additieven }\end{array}$ & $\begin{array}{l}\text { therapeutisch effect bij } \\
\text { histomoniasis }\end{array}$ & histomoniasis \\
\hline $2018-10$ & $\begin{array}{l}\text { mengsel van smaakstoffen, } \\
\text { propyleenglycol, glycerol, } \\
\text { technologische additieven }\end{array}$ & $\begin{array}{l}\text { sterk afwerend effect op } \\
\text { insecten inclusief mijten }\end{array}$ & bloedluis \\
\hline $2018-11$ & $\begin{array}{l}\text { mengsel van smaakstoffen, } \\
\text { propyleenglycol, glycerine en } \\
\text { technologische additieven }\end{array}$ & $\begin{array}{l}\text { antibacterieel effect tegen } \\
\text { pathogenen }\end{array}$ & Infecties bij pluimvee \\
\hline $2018-12$ & $\begin{array}{l}\text { Zwavelproduct, hoog gehalte } \\
\text { aan selenium, vitamine E en } \\
\text { zink }\end{array}$ & $\begin{array}{l}\text { vliegwerend, spierversterkend, } \\
\text { immuunversterkend. } \\
\text { Beïnvloedt de smakelijkheid } \\
\text { van het bloed en verandert de } \\
\text { geur van de huid. }\end{array}$ & Vlieg-werend \\
\hline $2018-13$ & silica & $\begin{array}{l}\text { Doodt alle luizen direct bij } \\
\text { aanraking. Lange werking tot } \\
12 \text { maanden. Niet giftig voor } \\
\text { mens en dier. }\end{array}$ & Bloedluis \\
\hline $2018-14$ & $\begin{array}{l}\text { Propyleenglycol, } \\
\text { Natriumchloride }\end{array}$ & $\begin{array}{l}\text { ondersteunt het herstel van uw } \\
\text { zieke vogel, neemt de pijn } \\
\text { weg, ontspant en zorgt ervoor } \\
\text { dat deze weer wilt gaan eten }\end{array}$ & Herstel na ziekte \\
\hline $2018-15$ & $\begin{array}{l}\text { aanvullend diervoeder voor } \\
\text { duiven en pluimvee op basis } \\
\text { van etherische oliën en } \\
\text { aromatische stoffen }\end{array}$ & $\begin{array}{l}\text { reinigende werking, bevordert } \\
\text { ademhaling en de } \\
\text { spijsvertering, preventief en } \\
\text { curatief, } 100 \% \text { natuurlijk }\end{array}$ & werkt tegen het geel \\
\hline
\end{tabular}


Bijvangst:

Tabel 2 Middelen bestaand uit verboden diergeneesmiddelen

\begin{tabular}{lll}
\hline Middel & Samenstelling & Indicatie \\
\hline $2018-16$ & $10 \%$ olaquindox & groeibevorderaar \\
\hline $2018-17$ & $10 \%$ zinkbacitracine & gezondheidbevorderaar \\
\hline $2018-18$ & arsalinic acid & groeibevorderaar \\
\hline $2018-19$ & monensin & anticoccidiose \\
\hline $2018-20$ & amprolium & anticoccidiose \\
\hline $2018-22$ & robenidine & anticoccidiose \\
\hline $2018-23$ & virginiamycine & groeibevorderaar \\
\hline $2018-24$ & dimetridazol & antiprotozoair \\
\hline $2018-25$ & dapson & antibioticum \\
\hline $2018-26$ & metronidazole 10\% & antiprotozoair \\
\hline $2018-27$ & Furaltadon, Tetracycline, Chlooramfenicol & antibiotica \\
\hline $2018-28$ & Furaltadon, Metronidazol, Tetracycline. & antibiotica en antiprotozoair \\
\hline
\end{tabular}

Tabel $3 \quad$ Middelen met in Nederland verboden biociden voor pluimvee

\begin{tabular}{lll}
\hline Middel & Samenstelling & Indicatie \\
\hline $2018-29$ & bendiocarb & bloedluis \\
\hline $2018-30$ & cypermethrin, tetrmethrin geraniol & bloedluis \\
\hline $2018-31$ & permethrin, tetramethrin, geraniol & tegen ongedierte bij vogels en honden \\
\hline $2018-32$ & permethrin, cypermethrin, tetratmethrin, geraniol & voor ongedierte bij honden en vogels \\
\hline $2018-33$ & piperonylbutoxide en pyrethrum & bloedluis \\
\hline
\end{tabular}

Tabel 4 Middelen voor lokale toedieningen met een diergeneeskundige claim

\begin{tabular}{lllll}
\hline Middel & Samenstelling & Indicatie & Toediening & Claim \\
\hline 2018-35 & $\begin{array}{l}\text { salicylzuur, koper, zink, zwavel } \\
\text { en lage pH }\end{array}$ & Tegen Mortellaro & lokaal & ter behandeling van acute \\
processen
\end{tabular}

Er is veel op de markt met een onwaarschijnlijke of diergeneeskundige claim en onduidelijke inhoud. Via siervogelsites is makkelijk aan verboden antibiotica te komen. Ook insecticiden die niet toegestaan zijn als biocide bij bv pluimvee worden verhandeld als middel tegen bloedluis. Er zijn in de lijst ook enkele omgevingssprays meegenomen omdat er daarbij werd aangegeven dat deze in aanwezigheid van de dieren kunnen worden gebruikt. Bij sprayen in aanwezigheid van de dieren kan het middel in voer en drinkwaterbakken terecht komen en zo in het dier.

Gezien de beperkte tijd van dit project zijn een aantal mogelijk interessante bronnen niet verder onderzocht. Gezien de veelheid aan producten en leveranciers is veel uitgebreider onderzoek nodig. Volgens de statuten van de VDDN, moeten deelnemende bedrijven minimaal GMP-plus gecertificeerd zijn. Ze raadden aan vooral aandacht te besteden aan bedrijven die zich direct richten op de veehouder, moeten aangesloten zijn bij GMP+ en SecureFeed, maar dat wordt vaak niet gedaan. 


\section{$4 \quad$ Conclusies}

- De gevolgde methode heeft duidelijk resultaten opgeleverd

- Er is veel op de markt met een sterke claim en onduidelijke inhoud

- Via sites gericht op diervogels en duiven is makkelijk aan verboden antibiotica te komen

- Insecticiden die niet toegestaan zijn als biocide bij bv pluimvee worden openlijk verhandeld

- Risico's: aanwezigheid verboden middelen, residuen in dierlijke producten, verboden diergeneeskundige of biocide claim 


\section{$5 \quad$ Aanbevelingen}

- Nader onderzoek naar de producten en producerende/verkopende bedrijven op de lijst

- Analyse van verdachte producten op samenstelling en aanwezigheid verboden middelen, m.n. voor producten die volgens het etiket/internet/etc. alleen natuurlijke middelen bevatten

- Na opvraag monsters 3 of 4 praktijkmonsters screenen met LC-HRMS. Na data-analyse wordt er m.b.v. databases gezocht naar 'verdachte' middelen

- Vooral aandacht naar bedrijven die zich direct richten op de veehouder

- Voortzetting van het project in 2022

- Opzet etiketeisen voor natuurlijke middelen 


\section{Bijlage 1 Risico's}

- Aanwezigheid verboden middelen

- Aanwezigheid onbekende toxines

- Residuen in dierlijke producten

- Product niet toegelaten in Nederland/ voor deze diersoort

- Verboden diergeneeskundige claim

- Verboden biocide claim 


\section{Bijlage 2 Verboden stoffen}

o.g.v. VERORDENING (EU) Nr. 37/2010 VAN DE COMMISSIE van 22 december 2009 betreffende farmacologisch werkzame stoffen en de indeling daarvan op basis van maximumwaarden voor residuen in levensmiddelen van dierlijke oorsprong.

\section{Tabel 2}

Verboden stoffen

\begin{tabular}{l|l}
\hline \multicolumn{1}{c|}{ Farmacologisch werkame stof } & \multicolumn{1}{c}{ MRL } \\
\hline Aristolochia spp. en daarvan afgeleide producten & Er kan geen MRL worden vastgesteld \\
\hline Chlooramfenicol & Er kan geen MRL worden vastgesteld \\
\hline $\mathbf{\nabla} \underline{\mathbf{B} 3 \mathbf{C}}$ & Er kan geen MRL worden vastgesteld \\
\hline & \\
\hline Colchicine & \\
\hline Dapson & Er kan geen MRL worden vastgesteld \\
\hline Dimetridazool & Er kan geen MRL worden vastgesteld \\
\hline Metronidazool & Er kan geen MRL worden vastgesteld \\
\hline Nitrofuranen (inclusief furazolidon) & Er kan geen MRL worden vastgesteld \\
\hline Ronidazool & Er kan geen MRL worden vastgesteld \\
\hline
\end{tabular}


Wageningen Food Safety Research Postbus 230

6700 AE Wageningen

T 0317480256

wur.nl/food-safety-research

WFSR-rapport 2021.020

口ising
De missie van Wageningen University \& Research is 'To explore the potential of nature to improve the quality of life'. Binnen Wageningen University \& Research bundelen Wageningen University en gespecialiseerde onderzoeksinstituten van Stichting Wageningen Research hun krachten om bij te dragen aan de oplossing van belangrijke vragen in het domein van gezonde voeding en leefomgeving. Met ongeveer 30 vestigingen, 6.800 medewerkers ( $6.000 \mathrm{fte}$ ) en 12.900 studenten behoort Wageningen University \& Research wereldwijd tot de aansprekende kennisinstellingen binnen haar domein. De integrale benadering van de vraagstukken en de samenwerking tussen verschillende disciplines vormen het hart van de unieke Wageningen aanpak. 



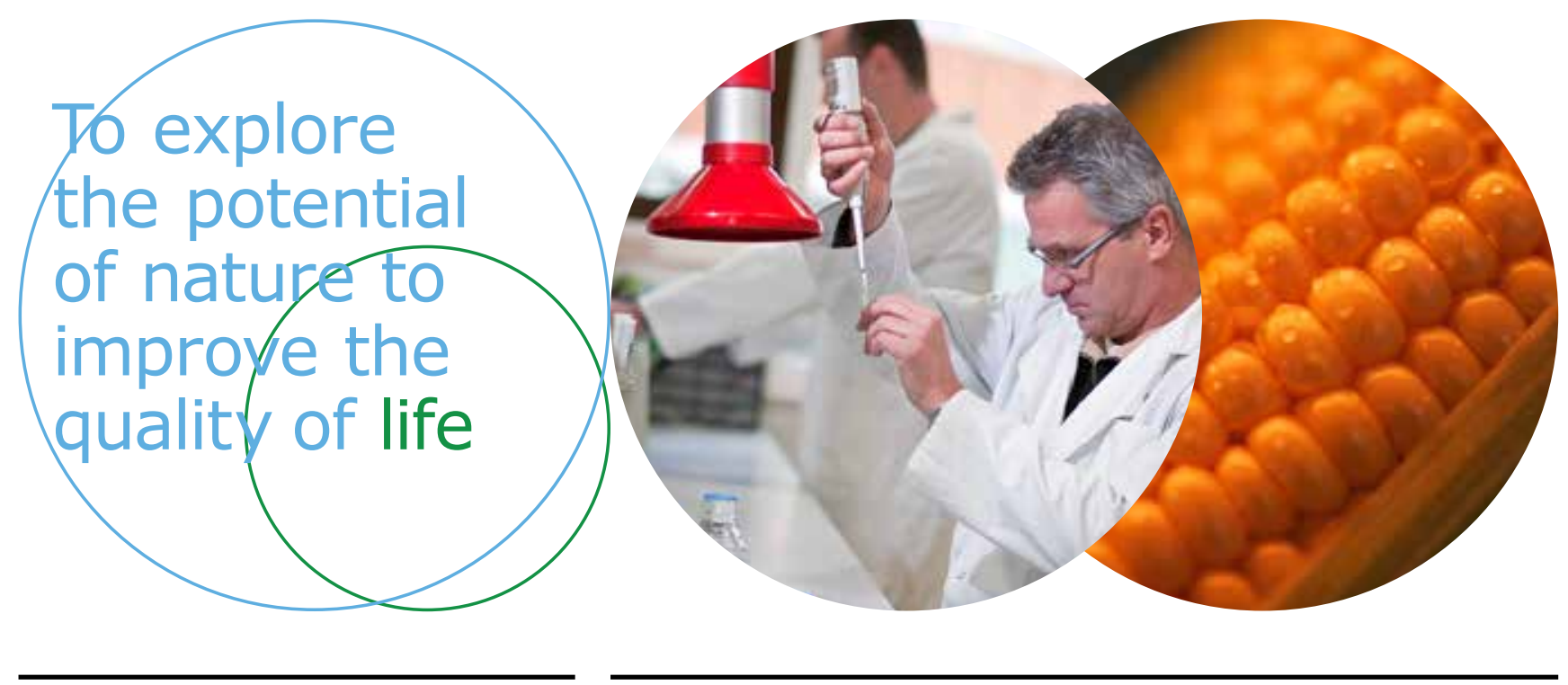

Wageningen Food Safety Research Postbus 230

6700 AE Wageningen

T 0317480256

wur.nl/food-safety-research

WFSR-rapport 2021.020
De missie van Wageningen University \& Research is 'To explore the potential of nature to improve the quality of life'. Binnen Wageningen University \& Research bundelen Wageningen University en gespecialiseerde onderzoeksinstituten van Stichting Wageningen Research hun krachten om bij te dragen aan de oplossing van belangrijke vragen in het domein van gezonde voeding en leefomgeving. Met ongeveer 30 vestigingen, 6.800 medewerkers ( $6.000 \mathrm{fte}$ ) en 12.900 studenten behoort Wageningen University \& Research wereldwijd tot de aansprekende kennisinstellingen binnen haar domein. De integrale benadering van de vraagstukken en de samenwerking tussen verschillende disciplines vormen het hart van de unieke Wageningen aanpak. 